\title{
Ciencias Espaciales, campo emergente en Honduras
}

María Cristina Pineda de Carías*

\section{RESUMEN}

En este artículo se presentan los principales hechos, argumentos y procedimientos que dieron lugar a la creación de la Facultad de Ciencias Espaciales de la UNAH. Como una consecuencia de que en el Acuerdo de aprobación de la nueva estructura académica universitaria no se hizo referencia explícita a la ubicación del Observatorio Astronómico Centroamericano de Suyapa, surgió la necesidad de recurrir al Consejo Universitario para que no sólo le diera ubicación y reconocimiento a esta unidad universitaria, sino el espacio académico institucional para que sus profesores y estudiantes pudieran continuar trabajando en un campo científico emergente. Para poner en contexto los hechos, se explica qué son las Ciencias Espaciales y cuáles los esfuerzos de la comunidad científica internacional liderados por la Oficina de Asuntos del Espacio Ultraterrestre de las Naciones Unidas, en procura del desarrollo de las ciencias espaciales sobre todo para beneficio de los paises en desarrollo.

Se presentan logros importantes alcanzados por el Observatorio Astronómico Centroamericano de Suyapa en Astronomía y Astrofísica, Ciencia y Tecnologías de la Información Geográfica, y Arqueoastronomía, campos todos éstos en los que sus profesores y estudiantes han tenido un reconocimiento nacional e internacional. Se citan los artículos de las nuevas leyes y reglamentos universitarios directamente relacionados con la creación y funcionamiento de una facultad o un centro universitario. Derivado de ello se incluye el procedimiento correspondiente, particularizando en el que dio lugar a la creación de la Facultad de Ciencias Espaciales. Entre las conclusiones se destacan, la flexibilidad de las nuevas leyes universitarias y el espacio que el Consejo Universitario como máximo organismo de gobierno universitario brinda al desarrollo académico institucional; los retos que profesores y estudiantes de la Facultad de Ciencias Espaciales tienen para sacar adelante esta nueva unidad.

Palabras clave: Universidad: UNAH, Observatorio Astronómico Centroamericano de Suyapa; facultades, centros universitarios; Ciencias Espaciales.

\footnotetext{
* Universidad Nacional Autónoma de Honduras. Facultad de Ciencias Espaciales. Decana. mcpinedacarias@gmail.com
} 


\section{ABSTRACT}

In this article we present the main facts, arguments and procedures that led to the creation of the Faculty of Space Sciences at the NAUH. As a consequence of the Resolution of adoption of the new university academic structure that made not explicit reference to the location of the Central American Suyapa Astronomical Observatory, it became necessary to appeal to the University Council to not only give her location and recognition of this university unit, but the institutional academic space for its faculty and students to continue working in an emerging scientific field. In order to contextualize the facts, what Space Science are and which the efforts of the international scientific community led by the Office for Outer Space Affairs of the United Nations in pursuing the development of space science, especially for the benefit of the developing countries, are explained.

We present significant achievements of the Central America Suyapa Astronomical Observatory in Astronomy and Astrophysics, Science and Geographic Information Technologies and in Archaeoastronomy, all these fields in which its faculty and students have had a national and international recognition. We mention the articles of the new laws and by laws directly related to the establishment and operation of a faculty or a university center. This includes derivative of the corresponding procedure, specifying the one that led to the creation of the Faculty of Space Sciences. Among the conclusions are, the flexibility of the new university laws and the space that the University Council, as governing body of university provides to the institutional academic development; the challenges staff and students of the Faculty of Space Sciences have to take this unit forward.

Key words: University: NAUH, Central America Suyapa Astronomical Observatory; faculty, university center; Space Science. 


\section{INTRODUCCIÓN}

Los primeros años del siglo XXI recogen en Honduras el período cuando el país en general y la Comunidad Universitaria en particular, reconocieron que ni la organización ni el funcionamiento de la Universidad Nacional Autónoma de Honduras (UNAH) realmente estaban contribuyendo a la investigación científica, humanística y tecnológica, así como a la difusión general de la cultura y al estudio de los problemas nacionales, o a la formación de profesionales capaces de participar en la transformación de la sociedad hondureña, para impulsar el desarrollo económico, político, social, humano y sostenible de Honduras.

En la historia de la UNAH se reconocen cuatro hitos importantes que la reforman. El primero ocurrido después del 14 de diciembre de 1845 cuando el Presbítero José Trinidad Reyes fundó la "Sociedad del Genio Emprendedor y del Buen Gusto", que luego se transformó en la "Academia Literaria de Tegucigalpa", y ésta a su vez se convirtió en la Universidad Nacional mediante Decreto del 13 de Septiembre de 1847. Era ésta una Universidad bajo inspiración eclesiástica según modelos tradicionales que provenían de la época colonial. El segundo hito reformador se dio cuando en 1882, el gobierno del Presidente Marco Aurelio Soto la integró dentro del Ministerio de Educación, orientada por la filosofía positivista y laica, destinada a la formación de profesionales. El tercer hito lo constituyó la conquista de la autonomía universitaria que quedó plasmada en el Decreto 170 del 15 de Octubre de 1957 contentivo de la Ley Orgánica de la Universidad Nacional Autónoma de Honduras. En los años recientes, el cuarto hito lo marcó la aprobación de una nueva Ley Orgánica de la UNAH mediante el Decreto Legislativo No. 209-2004 de fecha 17 de Diciembre de 2004, como parte de un movimiento promovido desde el interior mismo de la Universidad que se conoce como la cuarta reforma universitaria.

En el marco de esta nueva Ley Orgánica que entró en vigencia el 13 de Febrero de 2005 a partir de su publicación en el Diario Oficial La Gaceta (Ley Orgánica de la UNAH, 2005) y sus reformas (2006), el Congreso Nacional de la República de Honduras creó una Comisión de Transición para asegurar la reforma institucional de la UNAH, la organización de la nueva estructura universitaria, la instalación del nuevo gobierno universitario, la reforma académica y en general, la propia y correcta aplicación de la Ley.

En los momentos cuando la Comisión de Transición estaba estudiando el Modelo de Estructura que la UNAH debía tener para ubicar a cada unidad académica 0 administrativa en el sitio que le correspondía conforme a la nueva Ley Orgánica, y en los momentos también cuando al interior del Observatorio Astronómico 
Centroamericano de Suyapa de la Universidad Nacional Autónoma de Honduras (OACS/UNAH) se estaba tratando de participar en los procesos que hicieran de la reforma universitaria un proceso permanente, el Personal del OACS/UNAH se reunió en sesión de trabajo con la Comisión de Transición para hacer un planteamiento y responder a la pregunta, ¿Qué es el Observatorio Astronómico de la UNAH? En esa oportunidad se expuso sobre la historia de cómo nació el Observatorio Astronómico, cuál era su misión, visión, valores, su organización, cuáles eran las tareas académicas que el Personal del OACS desarrollaba en los campos de la Astronomía y la Astrofísica, la Percepción Remota, en Arqueoastronomía, en la Administración Académica. Con los argumentos presentados se concluyó que el OACS era el centro de la UNAH encargado de contribuir al desarrollo de la Ciencia Espacial en los campos de la Astronomía y la Astrofísica, Percepción Remota, Arqueoastronomía y otros afines, con calidad, pertinencia, innovación e impacto bidireccional en lo local, lo nacional, lo regional y lo universal, a través del desarrollo de actividades académicas de docencia, investigación, vinculación con la sociedad y administración académica (Pineda de Carías, 2008).

El 15 de mayo de 2008, la Comisión de Transición de la UNAH, a pocas horas de concluir el período de su existencia, adoptó el Acuerdo Número Trescientos Sesenta y Ocho (Comisión de Transición, 2008), mediante el cual aprobó la estructura organizativa y académica de las Facultades de la Universidad Nacional Autónoma de Honduras, creando las Facultades de Humanidades y Artes, Ciencias Sociales, y la de Ciencias, reorganizando las Facultades de Ciencias Económicas, Ciencias Médicas, Química y Farmacia, Ingenieria, Odontología y Ciencias Jurídicas, creando para su organización nuevas facultades y cancelando el Centro Universitario de Estudios Generales (CUEG). En ninguna parte de este Acuerdo, de manera explícita, se hizo referencia a la ubicación del Observatorio Astronómico Centroamericano de Suyapa de la Universidad Nacional Autónoma de Honduras.

La nueva estructura universitaria recién creada, inmediatamente puso en evidencia que para el OACS, además de la necesidad de tener que definirle una ubicación clara, un problema mayor lo constituía la amenaza de poder continuar desarrollando los diferentes campos académicos en los que y por los que sus profesores habian venido trabajando en los últimos quince años. El problema en realidad era, dar a conocer a toda la comunidad universitaria, ¿qué eran la Astronomía y la Astrofísica, la Percepción Remota, Arqueoastronomía, las Ciencias Espaciales? ¿En qué se beneficia el pueblo hondureño si un grupo de profesores universitarios se ocupan del estudio y la formación de profesionales de la Astronomía y la Astrofísica? ¿Dónde se utiliza la ciencia y las tecnologías de información geográfica para 
contribuir a resolver los problemas de la sociedad hondureña, particularmente cuando éstos se orientan hacia la percepción remota, los sistemas de información geográfica, el ordenamiento territorial? ¿Qué importancia tiene para Honduras y para la región centroamericana, conocer las formas en que los mayas utilizaban sus conocimientos astronómicos en las diferentes actividades de su vida cotidiana? ¿Cuál es la necesidad por la que todos estos campos debían ser desarrollados como parte de las actividades académicas de la UNAH? ¿Por qué todos estos campos específicos del conocimiento debían ser desarrollados en una unidad académico administrativa distinta a la de las facultades o centros universitarios existentes? En este artículo se explica cómo, la creación de la Facultad de Ciencias Espaciales (FACES) de la Universidad Nacional Autónoma de Honduras (UNAH) puede contribuir a que en Honduras, las presentes y futuras generaciones de ciudadanos se beneficien de los conocimientos y tecnologías espaciales actuales para mejorar sus condiciones de vida y el estado de desarrollo del país. Puedan también apropiarse y dominar estos conocimientos para que algunos de sus profesores, estudiantes y profesionales universitarios, participen con la comunidad científica internacional en la creación de nuevos conocimientos y en la innovación, uso y aplicación de los nuevos conocimientos y tecnologías espaciales que beneficien a la población mundial en general y contribuyan a la preservación de las condiciones de vida en el Planeta.

El trabajo recoge y sistematiza los argumentos, posiciones y acciones del personal del Observatorio Astronómico Centroamericano de Suyapa (OACS) que motivó que el Honorable Consejo Universitario de la UNAH, en su sesión ordinaria del mes de abril de 2009, aprobara la creación de la Facultad de Ciencias Espaciales en reconocimiento al funcionamiento del Observatorio Astronómico Centroamericano de Suyapa de la Universidad Nacional Autónoma de Honduras. Se destaca la flexibilidad de las nuevas leyes universitarias y el espacio que el Consejo Universitario, como máximo organismo de gobierno universitario, brinda al desarrollo académico institucional. Cuáles son los retos que profesores y estudiantes de la Facultad de Ciencias Espaciales tienen para sacar adelante esta nueva unidad académica administrativa de la UNAH.

\subsection{Ciencias Espaciales}

El lanzamiento y puesta en funcionamiento de los primeros satélites artificiales que desde finales de los años cincuenta orbitan la Tierra, permitieron a la Humanidad ampliar y mejorar sus conocimientos acerca del origen y evolución de los diferentes objetos astronómicos, así como entender mejor nuestro lugar en el Universo. Tener por primera vez una visión completa del Planeta Tierra para observar sus principales 
rasgos superficiales, las completas dimensiones de sus océanos, las características globales de su atmósfera, facilitó grandemente poder evaluar anticipadamente las dimensiones e impacto de huracanes, inundaciones 0 deslizamientos, posibilitando salvar vidas al localizar y establecer comunicación con personas aisladas a las que solamente los sensores remotos a bordo de plataformas espaciales podían detectar. Hizo posible la prospección y búsqueda de restos de antiguos asentamientos humanos desde el espacio, contribuyendo así a la preservación del Patrimonio de la Humanidad. A partir de entonces la Astronomía y la Ciencia Espacial básica han avanzado rápidamente llevadas por el advenimiento de la Era Espacial.

Las necesidades de nuevos desarrollos resultaron obvias a medida que los países hacían esfuerzos para beneficiarse del rápido progreso de la ciencia y la tecnología espacial. Pero estos procesos requerían de una completa innovación para el manejo de fuerzas de desarrollo donde ninguna experiencia previa estaba disponible. Aunque los modelos de nuevos desarrollos se aplicaban con diferentes niveles de éxito, un gran número de países en el mundo continuaba careciendo de recursos humanos, técnicos y financieros para realizar las actividades más básicas en este campo, tales como la operación de pequeños telescopios astronómicos en el ambiente de una universidad y hacer uso de tales facilidades en la investigación y la educación. La necesidad de hacer que los beneficios de las ciencias espaciales básicas estuvieran disponibles para todos los países, crecia urgentemente con el paso de cada año (Haubold y Wamstaker, 2004).

El Programa de las Naciones Unidas sobre Aplicaciones Espaciales, desde su inauguración en 1970, empezó a hacer esfuerzos para avanzar los conocimientos y experiencias de las aplicaciones espaciales alrededor del mundo. Se empezaron a hacer previsiones para que en los países se construyeran capacidades en educación e investigación, y para que los países en desarrollo empezaran a beneficiarse de estos progresos. En diciembre de 1982, la Asamblea General de la ONU decidió, por recomendación de la Segunda Conferencia de las Naciones Unidas sobre la Exploración y Utilización del Espacio Ultraterrestre con Fines Pacíficos (UNISPACE 82), que el Programa de las Naciones Unidas de Aplicaciones de la Tecnología Espacial, entre otras cosas, promoviera una mayor cooperación entre los países desarrollados y en desarrollo en materia de ciencia y tecnologías espaciales.

Fue así como para 1990 los enfoques se dirigieron principalmente, ya no sólo hacia las aplicaciones de la percepción remota de la Tierra, las aplicaciones de los satélites meteorológicos y de los satélites de comunicaciones, sino también a 
identificar la posible necesidad e importancia del crecimiento de pequeños grupos en las universidades y centros de investigación en los países en desarrollo en el campo de la astronomía y las ciencias espaciales. Esto condujo a la realización de un serie de Talleres de las Naciones Unidas y la Agencia Espacial Europea sobre Ciencia Espacial Básica, con una periodicidad anual para las diferentes regiones del mundo: Asia y el Pacífico, América Latina y el Caribe, África, el Oeste de Asia, y Europa.

En la Tabla 1 se presenta un Resumen de los Talleres sobre Ciencia Espacial Básica promovidas por las Naciones Unidas y la Agencia Europea Espacial. Aquí se detallan los años, las ciudades y los países en que se realizaron, y se da la referencia de los documentos que recogen los Informes presentados a la Asamblea General de las Naciones Unidas con las recomendaciones y observaciones de cada uno de los doce Talleres realizados entre 1991 a 2004. Los documentos de los informes se publicaron en los seis idiomas oficiales de las Naciones Unidas: inglés, español, árabe, chino, francés y ruso, encontrándose disponibles en Internet: http://www.unoosa.org/oosa/SAP/bss/index.html.

Tabla 1. Resumen de Talleres sobre Ciencia Espacial Básica promovidos por las Naciones Unidas y la Agencia Europea Espacial.

\begin{tabular}{|c|c|c|}
\hline AÑO & CIUDAD, PAIS & INFORME ONU \\
\hline 1991 & Bangalore, India & A/AC. $105 / 489$ \\
\hline 1992 & San José, Costa Rica y Bogotá, Colombia & A/AC. $105 / 530$ \\
\hline 1993 & Lagos, Nigeria & AVAC. 105/560/Add.1 \\
\hline 1994 & El Cairo, Egipto & AAC. $105 / 580$ \\
\hline 1995 & Colombo, Sri Lanka & AIAC. $105 / 640$ \\
\hline 1996 & Bonn, Alemania & AVAC. $105 / 657$ \\
\hline 1997 & Tegucigalpa, Honduras & AAC. $105 / 682$ \\
\hline 1999 & Mafrag, Jordania & AIAC. $105 / 723$ \\
\hline 2000 & Tolousse, Francia & AIAC. $105 / 742$ \\
\hline 2001 & Reduit, Mauritania & AlAC. $105 / 766$ \\
\hline 2002 & Córdoba, Argentina & AIAC. 105/784 \\
\hline 2004 & Beijing, China & AVAC. $105 / 829$ \\
\hline
\end{tabular}

Fuente: United Nations Office of Outer Space Affairs. United Nations/European Space Agency Basic Space Science Workshop: http://www.unoosa.org/oosa/SAP/bss/index.html

En el contexto de las necesidades para los países en desarrollo, desde el primero de estos talleres se definió que las ciencias espaciales debian abarcar: la Física Fundamental, la Astronomía y la Astrofísica, la Interacción Sol-Tierra y su influencia 
en el clima de la Tierra, los estudios planetarios y de sus atmósferas, y el origen de la vida y la exobiología. Esto con técnicas aplicables como herramientas para lograr la investigación espacial básica en observaciones ópticas con base en tierra y radio observaciones, telescopios ópticos con equipos asociados, percepción remota desde la tierra y desde el espacio, todas las mediciones desde las ventanas inaccesibles desde la Tierra y las cuales sólo podian ser hechas con el uso de instrumentos y telescopios en orbitas terrestres, y mediciones de los sitios desde cohetes, balones y plataformas satelitales.

El objetivo principal de estos talleres era: clarificar la importancia de un desarrollo autóctono para involucrarse en las ciencias espaciales para contribuir al desarrollo sostenible económico, social y cultural, no sólo en los países individuales, sino sobre una base global. En todas las etapas de esta serie de talleres, la excepcional colaboración entre los científicos de los países industrializados y en desarrollo, así como el apoyo sustantivo de los Gobiernos, de las Agencias Espaciales de Austria (ASA), Europa (ESA), Francia (CNES), Alemania (DLR), la Administración Nacional de Aeronáutica y del Espacio (NASA), el Comité de Investigaciones Espaciales (COSPAR), el Instituto de Ciencias Aeronáuticas y Espaciales de Japón (ISAS), la Unión Astronómica Internacional (IAU), el Centro Internacional de Física Teórica (ICTP), la Sociedad Planetaria (TPS) y la Organización de las Naciones Unidas (ONU), fueron críticas para el éxito alcanzado.

Resultado importante de las deliberaciones de más de un millar de científicos que participamos en los diferentes Talleres de Ciencia Espacial Básica, fue el desarrollo del modelo de un triplete para la implementación acelerada de la ciencia espacial, que en el caso de los países en desarrollo debería considerar:

- La disponibilidad de herramientas de investigación de un nivel que fuera significativo tanto para el desarrollo de la ciencia como para la infraestructura socioeconómica nacional, por ejemplo la instalación de pequeños telescopios en las universidades.

- Materiales de enseñanza que permitieran que la ciencia espacial básica pudiera ser introducida a nivel de los cursos generales fundamentales de la educación superior.

- Aplicación de materiales producto de investigaciones originales de la ciencia espacial básica, tales como programas de observación de estrellas.

EI VII Taller de las Naciones Unidas y la Agencia Espacial Europea sobre Ciencia Espacial Básica, se dedicó a los Telescopios y Satélites Astronómicos Pequeños para la Educación y la Investigación (Informe VII Taller UN/ESA Ciencia Espacial 
Básica, 2007). Fue realizado en la ciudad de Tegucigalpa, Honduras, del 16 al 20 de junio de 2007, siendo organizado conjuntamente por la Oficina de Asuntos del Espacio Ultraterrestre de las Naciones Unidas, la Agencia Espacial Europea (ESA), la Sociedad Planetaria (TPS), y el Observatorio Astronómico de la Universidad Nacional Autónoma de Honduras, que actuó como anfitrión en nombre del Gobierno de Honduras.

El objetivo del VII Taller era evaluar los logros de los seis Talleres sobre Ciencia Espacial Básica anteriores, celebrados de 1991 a 1996, e inaugurar el Observatorio Astronómico para Centro América ubicado en Tegucigalpa. El programa comprendió la presentación de comunicaciones científicas sobre los siguientes temas: a) El Sistema Solar y la vida en la Tierra; b) Investigaciones punteras con pequeños telescopios; c) Misiones de satélites astronómicos y resultados obtenidos de sus bases de datos; d) La cooperación internacional y regional en ciencia espacial básica; e) Programas y proyectos en el marco de la futura III Conferencia de las Naciones Unidas sobre la Exploración y Utilización del Espacio Ultraterrestre con Fines Pacíficos (UNISPACE III); y f) La inauguración del Observatorio Astronómico Centroaméricano en Honduras.

Asistieron al VII Taller de Tegucigalpa ochenta (80) astrónomos y científicos espaciales de los veintiocho países siguientes: Alemania, Australia, Austria, Canadá, Colombia, Costa Rica, Cuba, Egipto, El Salvador, Eslovaquia, España, Estados Unidos de América, Francia, Guatemala, Honduras, India, Indonesia, Italia, Japón, Marruecos, México, Nicaragua, Panamá, Polonia, Sri Lanka, Túnez, Uruguay y Zambia. En la ceremonia de inauguración pronunciaron discursos el Presidente de Honduras, C. R. Reina Idiáquez, en nombre del Gobierno de Honduras, M. C. Pineda de Carías, en nombre del Observatorio Astronómico de la Universidad Nacional Autónoma de Honduras, H. J. Haubold, en nombre de la Oficina de Asuntos del Espacio Ultraterrestre, W. Wamsteker, en nombre de la Agencia Espacial Europea, y L. Friedman, en nombre de La Sociedad Planetaria.

Entre las observaciones y recomendaciones del VII Taller de Ciencia Espacial Básica realizado en Tegucigalpa merece destacar las siguientes:

- Todos los participantes reconocieron la importancia de las oportunidades de la futura UNISPACE III. Gracias a los logros de los seis talleres sobre ciencia espacial básica, se habían puesto en marcha en todo el mundo actividades regionalmente apreciables. Las correspondientes a América Central habían culminado con la inauguración del telescopio "René Sagastume Castillo" en el Observatorio Astronómico de Suyapa para América Central. Esta nueva 
instalación, creada en Honduras y abierta a todos los científicos centroamericanos, demuestra con claridad que es posible acelerar la participación de los países en desarrollo en la ciencia espacial básica.

- Se señaló que para continuar y estimular más a fondo las actividades relacionadas con la ciencia espacial básica en los países en desarrollo, así como para mantener la dinámica alcanzada, era decisivo cuidarse no sólo de fomentar las actividades de investigación, sino también crear en la ciudadanía una actitud amplia de apoyo a dicha ciencia espacial, mediante programas de extensión. Tal apoyo permitiría ampliar y mantener la participación directa de los países en desarrollo en las actividades avanzadas. Esto podría lograrse únicamente con un enfoque en tres etapas, que tuviera en cuenta los siguientes puntos: a) Educación en ciencia espacial básica; b) Mayor desarrollo de determinados centros de investigación y educación a nivel local (y regional), como los observatorios modernos de proporciones moderadas integrados en redes; y c) Acceso directo a instalaciones dedicadas a la ciencia espacial básica de avanzada.

- Como estos tres puntos definían con claridad una forma práctica y bien estructurada de acelerar la participación de los países en desarrollo en las actividades de la ciencia espacial básica, constituía un reto importante para el próximo decenio determinar los procedimientos y proporcionar los medios de crear un entorno propicio para dicha participación a escala regional y mundial.

- Los temas de investigación para utilizar pequeños telescopios eran los siguientes: a) La estructura y evolución estelares, mediante el estudio de la variabilidad a largo plazo de las estrellas binarias eclipsantes y la observación de las variaciones intrínsecas; b) La detección y el estudio de los objetos cercanos a la Tierra; c) La detección y el estudio de los cometas, asteroides y otros cuerpos pequeños del sistema solar; d) Estudios duraderos de la meteorología de planetas distintos de la Tierra; e) El descubrimiento y estudio de fenómenos de corta duración en el Universo, como las supernovas, las novas y otros fenómenos explosivos; f) Los desechos espaciales; g) La predicción de la meteorología espacial mediante la observación del Sol.

- Dado que todos los instrumentos necesarios para estas actividades tenían amplia aplicación en muchas y numerosas esferas de actividad humana en un mundo tecnológicamente avanzado, el aumento consiguiente de la base de conocimientos de un país representaba una importante expansión de la labor educativa.

- La iniciativa de instalar en Centro América el primer observatorio astronómico, tuvo su origen en Honduras al comienzo de los años noventa tras una recomendación formulada en el II Taller sobre Ciencia Espacial Básica 
celebrado en 1992 en Colombia y Costa Rica. Dicha iniciativa se basaba en una estrategia de cooperación regional permanente entre las universidades nacionales de América Central y de colaboración intensa con astrónomos y centros de investigación astronómica prestigiosos a nivel internacional. Desde 1994 funcionaba en la Universidad Nacional Autónoma de Honduras, en Tegucigalpa, un observatorio astronómico provisional. Esta dependencia académica, provista de un telescopio computarizado de $42 \mathrm{~cm}$ y equipo auxiliar, se utilizó para poner en marcha un programa de capacitación de investigadores y técnicos de América Central. Se estaban preparando varios acuerdos de cooperación con instituciones regionales e internacionales, destinados a continuar desarrollando la ciencia espacial básica en la región. Durante el VII Taller se inauguró el Observatorio Astronómico Centroamericano de Tegucigalpa dedicándole el telescopio "René Sagastume Castillo" del observatorio de Suyapa paraAmérica Central.

\subsection{El Observatorio Astronómico Centroamericano de Suyapa (OACS)}

El Programa de Maestria en Astronomía y Astrofísica para Centroamérica surgió como parte del proyecto de la Universidad Nacional Autónoma de Honduras, para contribuir al establecimiento de la Astronomía y la Astrofísica como un campo académico dentro de la región (Pineda de Carías, M. C., 2001). En 1997, el mismo año que se oficializó la apertura del OACS, se oficializó también la apertura del campo académico de la Astronomía y Astrofísica en la UNAH, y del programa de maestría, el cual se abrió formalmente en 1998 para estudiantes centroamericanos graduados de las carreras de física, matemáticas e ingeniería. Entre 1998 y 2009, cuatro promociones se estudiantes se matricularon y se graduaron en el Programa de Maestría en Astronomía y Astrofísica (MAA). De los estudiantes que inicialmente se matricularon en cada promoción, los que lograron graduarse hoy son profesores del OACS; sin embargo los que no lograron completar sus estudios fue porque, o no aprobaron las asignaturas, o carecían de los recursos económicos suficientes para dedicarse exclusivamente a sus estudios, viéndose obligados a abandonar el programa.

Los estudiantes de la MAA, inicialmente unos estudiaron con beca de la Organización de Estados Americanos, pero al final, todos obtuvieron puestos de profesores auxiliares en el OACS. Los profesores de la MAA en su mayoría han sido profesores visitantes provenientes de observatorios astronómicos, centros de investigación o universidades de Argentina, Brasil, España, Chile, Cuba, México, Estados Unidos, Costa Rica, El Salvador. Ellos fueron seleccionados de acuerdo a 
su formación, experiencia y campo de especialización, convirtiéndose esto en una de las mayores fortalezas del programa. Los profesores visitantes, se trasladaban de sus países a Tegucigalpa durante tres o cuatro semanas, para impartir de manera intensiva sus asignaturas. Los temas de investigación para las tesis fueron seleccionados por los mismos estudiantes, y para el ochenta por ciento de ellos se consiguió financiamiento para que realizaran pasantías o estancias de un mes, seis meses y hasta un año, en los centros de trabajo de los profesores tutores. Los financiamientos principalmente fueron obtenidos de la Unión Astronómica Internacional (IAU) y de la UNAH.

La eficiencia terminal de la MAA fue de 100\% lográndose graduar a todos los estudiantes que completaron su plan de estudios y sus proyectos de investigación como documentos de tesis. Las líneas de investigación y los temas de tesis fueron: 1) El Sol:Actividad Solar: Análisis de la relación entre la intensidad de fondo de cielo como indicador de eyecciones coronales y los efectos geomagnéticos derivados. 2) Sistema Solar: asteroides binarios: Asteroides binarios cercanos a la Tierra. 3) Sistema Solar: Planetas Extrasolares: Dinámica de planetas extrasolares. 4) Sistema Solar: Dinámica Planetaria: Estructuras dinámicas en la región exterior a Saturno. 5) Estrellas: Espectroscopia Estelar: Análisis espectroscópicos de la Estrella Binaria HD161741 y de su material circumestelar. 6) Estrellas: Espectroscopia Estelar: 48 Librae: Variaciones espectroscópicas. 7) Estrellas: Fotometría y Espectroscopia: Emisiones máseres en regiones de formación de estrellas de gran masa: ¿trazadores de discos o de jets? 8) Galaxias: Agujeros negros súper masivos: Agujeros negros súper masivos en el centro de galaxias de disco y su relación con propiedades globales de las galaxias que los albergan. 9) Galaxias: Cúmulos estelares: Propiedades espectrales integradas de cúmulos estelares en las nubes de Magallanes. 10) Astrometría: Técnicas de Arqueoastronomía: Búsqueda a través de un modelo por ordenador de alineamientos astronómicos entre el Planeta Venus, Altares $G$ y estelas ubicadas en la Gran Plaza del Parque Arqueológico de Copan Ruinas, Honduras.

Después de un proceso de autoevaluación y acreditación regional, el Consejo Superior Universitario Centroamericano (CSUCA) le otorgó a la Maestría Académica en Astronomía y Astrofísica de la Universidad Nacional Autónoma de Honduras certificación de haber concluido satisfactoriamente el proceso de evaluación en el marco del Sistema de Carreras y Postgrados Regionales Centroamericanos SICAR-CSUCA, por lo cual se le otorgó el reconocimiento de Programa Regional Centroamericano por un período de cinco años a partir del 29 de noviembre de 2006 (Acta LXXX Sesión Ordinaria CSUCA, 2006). Luego de este reconocimiento, un nuevo Plan de Estudios fue aprobado por el Consejo de 
Educación Superior de la UNAH (Acuerdo Consejo Educación Superior, 2008), dando lugar a la apertura de la Maestría Regional Centroamericana de Astronomía y Astrofísica (MARCAA), la cual inició actividades para la primera promoción a finales del año 2008.

El nuevo Plan de Estudios (Plan de Estudios MARCAA, 2008) tiene cuatro ejes, uno de Fundamentos de Astronomía y Astrofísica que comprende nueve asignaturas: Fundamentos de Astronomía y Astrofísica, Estructura y Evolución Estelar, Atmósferas Estelares, Estructura Galáctica y Dinámica Estelar, Medio Interestelar, Astronomía Extragaláctica, Sistema Solar, Física Solar y Cosmología Observacional. Un segundo eje para que los estudiantes se orienten, hacia la Astrofísica Teórica con las asignaturas de Física Nuclear y de Partículas, Procesos Radiativos y Transferencia de Radiación, Física de Plasmas y Relatividad General y Aplicaciones, o hacia la Astrofísica Observacional con las asignaturas de Instrumentación Astrofísica, Procesos Radiativos y Transferencia de Radiación, Técnicas de Fotometría, Espectroscopia y Técnicas de Espectrometría. El tercer eje dedicado a que los alumnos tengan una segunda orientación, seleccionada entre la Arqueoastronomía o la Percepción Remota, como otros campos que se desarrollan en el OACS/UNAH. Y el cuarto eje, el de la Investigación, transversal a lo largo de toda la carrera que comprende las asignaturas: Introducción a la Investigación Astrofísica, Comunicación de Resultados Científicos, Técnicas de Manejo y Tratamiento de Datos, Problemas Contemporáneos del Campo de la Investigación, Educación en Astronomía, para terminar con el Proyecto de Investigación.

El segundo postgrado que se puso en funcionamiento en el OACS/UNAH fue la Maestría en Ordenamiento y Gestión del Territorio (MOGT), aprobado por el Consejo de Educación Superior para empezar a funcionar en Septiembre de 2005 (Acuerdo de Educación Superior, 2005). Esta Maestría surgió como una respuesta a las demandas de capacitación y formación planteadas por docentes y estudiantes de diferentes carreras de la UNAH, y de profesionales de otras instituciones públicas y privadas de Honduras que en su diario quehacer utilizaban imágenes satelitales, fotografías aéreas y datos geográficos de diferentes tipos o que tenían que preparar mapas con usos y aplicaciones variadas.

El Plan de Estudios (Plan de Estudios MOGT, 2005) se diseñó obedeciendo a tres directrices. La primera, que ubica la carrera dentro de la plataforma global que las Naciones Unidas, que por medio de la Oficina de Utilización del Espacio Ultraterrestre con Fines Pacíicos, venía promoviendo para la formación en Ciencia y Tecnología Espaciales (Remote Sensing and Geographic Information System Education Curriculum, 2003), específicamente en campos orientados al uso y 
aplicación de la Teleobservación de la Tierra, los Sistemas de Información Geográfica y de los Sistemas de Geoposicionamiento Global. La segunda, que tomó en cuenta la experiencia académica y de profesionalización del Departamento de Geografía de la Universidad de Alcalá, España, que por más de quince años venía desarrollando programas de postgrados en Cartografía, Sistemas de Información Geográfica y Teledetección (Departamento de Geografía UAH, 2004) para beneficio de los españoles pero también de estudiantes provenientes de los países latinoamericanos. La tercera, que consideró la capacidad instalada y la experiencia del Observatorio Astronómico Centroamericano de Suyapa que por medio de su Laboratorio de Percepción Remota (Pineda de Carias, M. C., 2001) había venido desarrollando cursos cortos y seminarios para estudiantes y docentes universitarios, pero también para profesionales de instituciones tales como la Secretaria de Recursos Naturales y Ambiente, la Secretaría de Agricultura y Ganadería, el Instituto Geográfico Nacional, la Dirección Ejecutiva de Catastro, el Servicio Nacional de Acueductos y Alcantarillados, entre otras, que necesitaban ser capacitados en el uso, manejo y análisis de datos geoespaciales; oferta a la que hay que agregar que como resultado de una investigación de campo para identificar prioridades, reflejó una necesidad de orientar estos estudios de postgrado hacia el ordenamiento territorial.

\section{El Plan de Estudios se aprobó para ser desarrollado en el término de dos años, en} 18 asignaturas más un Proyecto de Investigación. Las asignaturas se agrupan en cinco ciclos: el Ciclo 1 de Geografía y Fundamentos de Ordenamiento Territorial que comprende las asignaturas: Geografía y Ordenación del Territorio, y Fundamentos de Ordenamiento Territorial; el Ciclo 2 de Geodesia y Cartografía, que comprende las asignaturas: Fundamentos de Geodesia y Cartografía, Fotogrametría y Sistemas de Geoposicionamiento Global, Mapas: Diseño, Composición, Trazado e Impresión, y Atlas Electrónicos y Publicación de Mapas en la Web; el Ciclo 3 de Sistemas de Información Geográfica, que comprende las asignaturas: Fundamentos de Sistemas de Información Geográfica, Sistemas de Información Geográfica Ráster, Sistemas de Información Geográfica Vector, y Programación Aplicada a Entorno de Sistemas de Información Geográfica; el Ciclo 4 de Percepción Remota, que comprende las asignaturas: Principios Físicos de Percepción Remota, Plataformas Sensores y Teledetección Hiperespectral, Interpretación Visual de Imágenes, y Procesamiento e Interpretación Digital de Imágenes; el Ciclo 5 de Ordenamiento Territorial que comprende las asignaturas: Administración del Territorio y Aplicaciones, Planificación Territorial y Aplicaciones, y Gestión Territorial y Aplicaciones; una asignatura dedicada a la Práctica Profesional y otra dedicada al Proyecto de Investigación (tesis), completan el Plan de Estudios. 
De la primera promoción de la MOGT se graduaron dos estudiantes, uno con el tema: Regionalización de Honduras: hacia la construcción de regiones-plan a través del análisis espacial cuantitativo; y el otro con el tema: Análisis Multitemporal de la Cobertura de la Tierra en la Cuenca del Valle de Jesús de Otoro entre los años 20002006 aplicando técnicas de teledetección. La causa del bajo número de estudiantes graduados obedeció a varias razones, el bajo rendimiento académico de los estudiantes, pero sobre todo a la incapacidad de los estudiantes de poder financiarse los costos del postgrado, o poder atender las responsabilidades académicas atendiendo simultáneamente a otro trabajo. Para minimizar los problemas encontrados con la primera promoción de la MOGT, como una estrategia para el desarrollo de la segunda promoción se propuso la firma de un Convenio Marco de Cooperación Internacional entre la UNAH y la Universidad de Alcalá de España (Convenio Marco UNAH-UAH, 2007), y un Convenio Especifico entre el OACS/UNAH y el Departamento de Geografía de la Universidad de Alcalá (Convenio Específico OACS/UNAH-DG/UAH, 2007). Ambos convenios se firmaron con el apoyo del Programa de Cooperación con Centroamérica de la Universidad de Alcalá y la Vicerrectoría de Relaciones Internacionales de la UNAH. En la Convocatoria de la Agencia Española de Cooperación Internacional para el Desarrollo se presentó el Proyecto Docente para desarrollar la Segunda Promoción de la MOGT, el cual fue aprobado para el año 2008 (PCl-AECID 2008) y su renovación en el 2009 (PCI-AECID 2009). Este apoyo financiero permitió otorgar becas a todos los estudiantes de la MOGT, los cuales se espera completen sus estudios en el segundo semestre del 2010. Los Profesores de la MOGT en su mayor parte son profesores del Departamento de Geografía de la Universidad de Alcalá; pero también son profesores de otras universidades latinoamericanas como la Universidad de Luján de Argentina y las Universidades de Guadalajara y de Sinaloa de México. El resto del personal docente y la Coordinadora Académica son profesores del OACS/UNAH.

Todos los Profesores del OACS/UNAH, cada uno dentro de su campo de interés, colaboran en el desarrollo de proyectos de investigación, desarrollo e innovación como parte de su Carga Académica. Los resultados de estos proyectos se publican en revistas especializadas arbitradas nacionales e internacionales. También los resultados de estos proyectos se aplican en la UNAH o en instituciones gubernamentales del país. A manera de ejemplo se puede mencionar que sólo en el año académico 2009 se encuentran en desarrollo diecisiete proyectos de investigación, de los cuales cuatro tienen financiamiento internacional:

1) Desarrollo de nuevas tecnologías para la protección y preservación del patrimonio cultural de hábitat humanos en Honduras (PCI-AECID); 
2) Red de Laboratorios de Tecnologías de la Información Geográfica: LatinGEO (Proyecto UPM);

3) Redes Temáticas en Infraestructura de Datos Espaciales y e-learning (Proyecto UPM);

4) Red Geodésica GPS de Tegucigalpa (Proyecto AM). Uno se desarrolla con el apoyo financiero de la Dirección de Investigación Científica de la UNAH;

5) Detección de cambios por cobertura y uso de la tierra del occidente de Honduras usando datos geoespaciales (Beca Sustantiva de Investigación No. 01-BSI-2007).

Los doce proyectos restantes se desarrollan con los fondos del OACS/UNAH:

6) La influencia de la Luna en los procesos agrícolas y en el tratamiento y explotación del bosque;

7) Búsqueda de órbitas en planetas extrasolares;

8) Efecto sobre la rotación de Venus debido al impacto de un anillo de gas en expansión;

9) Un enfoque latinoamericano sobre el desarrollo y el calentamiento global, a partir del clima espacial;

10) Diseño de un Radiotelescopio para observación de galaxias;

11) Detección de máseres en regiones de formación de estrellas de gran masa;

12) Construcción de una base de espectros patrones de cúmulos estelares en las Nubes de Magallanes;

13) Caracterización de las condiciones de observación astronómica del OACS/UNAH;

14) Educación enAstronomía;

15) Infraestructura de Datos Espaciales de Honduras;

16) Modelo de Realidad Virtual del Centro Histórico del Distrito Central - Parte II; y

17) ProyectoArqueoastronomía Maya.

Todos estos proyectos tienen como requisito estar registrados en la Dirección de Investigación Científica de la UNAH.

Para vincular a la Universidad con la Sociedad, todos los profesores e instructores desarrollan varios proyectos dentro de los campos principales de trabajo ya establecidos en el OACS. Así en Astronomía y Astrofísica, por casi una década se vienen desarrollando dos veces a la semana el Proyecto de "Visitas al OACS/UNAH" y los días viernes el de las "Noches Astronómicas". Se cuentan en varios miles las personas que entre estudiantes de escuelas primarias, secundarias y universitarios, profesores, padres de familia, comunicadores sociales y público en 
general, anualmente visitan el OACS/UNAH. Ellos llegan para escuchar conferencias, realizar observaciones astronómicas con el telescopio para ver el Sol, la Luna, los planetas, estrellas, cúmulos globulares, nebulosas y galaxias; así como también para realizar observaciones astronómicas en las fechas de eventos especiales tales como de eclipses lunares y solares, equinoccios, solsticios o pasos del Sol por el cenit. Las efemérides astronómicas de todos estos astros y de eventos que son visibles desde nuestro territorio se publican mensualmente.

En el campo de la Ciencia y las Tecnologías de la Información Geográfica se mantiene el Sistema de Información Geográfica del OACS/UNAH mediante el cual se ha puesto a disposición de profesores y estudiantes universitarios, datos geoespaciales de Honduras y de Centroamérica; se participa también en la Comisión Interagencial de Datos Espaciales adscrita a la Secretaría de Gobernación y Justicia; y en el Consejo Departamental de Ordenamiento Territorial de Francisco Morazán, presidido por la Gobernación Política. En el campo de la Arqueoastronomía, se mantiene un Programa de Visitas al OACS/UNAH para presentar conferencias y explicaciones de las formas en que se piensa que los mayas realizan sus observaciones astronómicas, particularmente utilizando las estelas, de las cuales una réplica de la Estela $B$ de Copán se tiene en los predios del OACS/UNAH. También para guías y turistas que visitan las Ruinas de Copán, en las fechas de eventos solares importantes se presentan conferencias de Arqueoastronomía y se realizan observaciones astronómicas en el Parque Arqueológico de Copán Ruinas.

Todas las asignaturas que se imparten en el OACS/UNAH, sean éstas de pregrado o de postgrado, se desarrollan en dos modalidades. Una, la modalidad presencial, con clases teóricas y actividades prácticas que requieren la presencia física del profesor o el instructor ya sea en el aula de clases, el laboratorio o el observatorio astronómico. La otra, la modalidad virtual, donde los contenidos programáticos, las clases, actividades prácticas variadas y hasta los exámenes se realizan sobre una plataforma educativa virtual (Moodle) a la que los estudiantes acceden vía Internet desde la página web del respectivo departamento académico que las imparte. Esto tiene el doble propósito de introducir a estudiantes y profesores al uso de las nuevas tecnologías de la información y las comunicaciones para desarrollar con calidad, procesos de aprendizaje, así como también utilizar formas alternas cuando por causas externas las actividades no se pueden realizar en el campus universitario. Para los estudiantes de pregrado y como parte de la oferta de educación general, los profesores del OACS/UNAH imparten asignaturas a los estudiantes de todas las carreras que la UNAH ofrece en la Ciudad Universitaria de Tegucigalpa. Cada una de estas asignaturas se desarrolla conforme "jornalizaciones" que responden a un 
Programa Analítico debidamente actualizado y a un Calendario Académico aprobado para cada período. Los profesores e instructores de Astronomía y Astrofísica desde 1995 imparten la asignatura AN111 Introducción a la Astronomía en varias secciones que ahora se inician desde tempranas horas de la mañana y duran hasta las últimas horas de la tarde; los profesores de Ciencia y Tecnologías de la Información Geográfica imparten las tres nuevas asignaturas generales que en el 2008 aprobó el Honorable Consejo Universitario: CTE111 Introducción a la Percepción Remota, CTE112 Introducción a los Sistemas de Información Geográfica y CTE113 Introducción a los Sistemas de Geoposicionamiento Global. En el campo de la Arqueoastronomía, los profesores imparten varias secciones de la otra asignatura general que el Honorable Consejo Universitario aprobó el 2008, la asignatura AQA111 Introducción a la Arqueoastronomía. Entre todas las asignaturas de pregrado y de postgrado, cada período académico el OACS/UNAH atiende a una población estudiantil cercana a los 500 estudiantes, a la que hay que sumar y por lo novedoso de los campos que se ofrecen, a algunos profesores 0 profesionales universitarios ya graduados.

En materia de administración académica funciona la Dirección del OACS/UNAH como la instancia responsable de la organización, dirección, supervisión y evaluación de todas las actividades que realiza el personal docente, administrativo y de servicio. Al igual que en cualquier facultad o centro universitario, la Dirección del OACS administra con transparencia y eficacia sus recursos y gestiona los medios materiales de conformidad con un Plan Operativo Anual y un Presupuesto aprobado por los Órganos de Gobierno de la UNAH. A estos instrumentos de gestión se les da continuo seguimiento haciéndose evaluaciones periódicas que se elevan a las autoridades universitarias por medio de informes. Se coopera con los demás órganos de la Universidad en la realización de sus funciones y la relación con otras dependencias académicas o administrativas de la universidad, o con organismos nacionales e internacionales se mantiene a través de la correspondencia recibida y enviada, la cual es registrada y archivada por el personal de la Secretaria.

La Dirección del OACS organiza y propone a la Rectoría el nombramiento o la contratación del personal docente, de administración y de servicio conforme lo establecido en el Estatuto del Docente y el Contrato Colectivo; para ello, en la Administración del OACS se preparan y se lleva el control de las acciones de personal y presupuestarias a las que se les da seguimiento hasta completarlas. Solicitudes de contrato o nombramiento, Requisiciones de pago, Planillas de pago, son algunas de las acciones realizadas. En apoyo a estos servicios, se han organizado para su funcionamiento, el Consejo Local de Carrera Docente y una 
Comisión de Concurso. Obedeciendo a la departamentalización obligatoria establecida en la Ley Orgánica de la UNAH para todas las facultades y centros universitarios, los servicios académicos del OACS se han organizado por campos académicos, de manera que los profesores están agrupados en uno de los tres Departamentos, el de Astronomía y Astrofísica (DAAF), el de Ciencia y Tecnologías de la Información Geográfica (DCTIG), y el de Arqueoastronomía (DAQA). Para cada uno de estos Departamentos se ha designado un Profesor que actúa como Jefe para organizar, dirigir, supervisar y evaluar las actividades del Departamento y de los profesores e instructores. Al inicio de cada uno de los tres períodos académicos del año, en sesión de profesores de Departamento, se asigna la Carga Académica que comprende actividades de docencia, investigación, vinculación con la sociedad y administración académica. Buscando el mejoramiento continuo y la calidad, Informes de autoevaluación son preparados al final de cada período por cada uno de los profesores e instructores, y un informe consolidado del Departamento se presenta a la Dirección bajo indicadores específicos de los logros alcanzados y las limitaciones enfrentadas.

La Dirección del OACS coordina el proceso académico y administrativo de todas las unidades adscritas, por lo que un Informe integral de los Departamentos y Carreras y las secciones administrativas lo prepara para efectos de ser enviado a la Dirección de Desarrollo Institucional de la Universidad. El desarrollo de las actividades docentes del OACS se enmarcan, en el caso de las Carreras de Postgrado en los Planes de Estudio aprobados por el Consejo de Educación Superior, a propuesta de la Dirección del OACS, y en el caso de las asignaturas de servicio en los programas actualizados que se han presentado a la Dirección de Docencia y al Consejo Universitario para su aprobación, a propuesta de la Dirección del OACS. Una página web: http://www.oacs-unah.edu.hn se mantiene en servicio para informar continuamente, con transparencia y rendición de cuentas sobre las diferentes actividades realizadas en el OACS. Un documento de MemoriaAnual de Actividades se prepara en la Dirección del OACS al final del año académico. Es desde la Dirección del OACS donde se promueven y organizan actividades de investigación, vinculación con la sociedad, de formación permanente de los docentes de los Departamentos y de las Carreras.

A lo largo de cada período académico se participa en los procesos de matrícula, formación de expedientes de los estudiantes y demás acciones de gestión académica, coordinando actividades con el Sistema de Ingreso, Permanencia y Egreso de los estudiantes, tanto de grado como de postgrado. También desde la Dirección del OACS se coordinan los servicios para mantener y mejorar las instalaciones y espacios físicos, mobiliario, equipo de oficina y materiales 
necesarios para el desarrollo de las actividades académicas.

\subsection{Reglamentación relativa a la creación de facultades o centros universitarios en la UNAH}

La inclusión del Observatorio Astronómico Centroamericano de Suyapa en la nueva estructura académica de la UNAH, fue planteada como un reconocimiento de esta unidad académica administrativa, como una facultad o un centro universitario de la UNAH.

La revisión de las leyes y reglamentos universitarios vigentes, en los asuntos directamente relacionados con la creación y el funcionamiento de una facultad o un centro universitario, contiene lo siguiente:

Ley Orgánica de la Universidad Nacional Autónoma de Honduras $(2005,2006)$ Los órganos de Gobierno de la UNAH pueden ser de cuatro tipos: a) Del Nivel de Dirección Superior: El Consejo Universitario y la Junta de Dirección Universitaria; b) Del Nivel Ejecutivo y Académico: La Rectoría, las Facultades, los Centros Universitarios y Regionales, y los Departamentos y Carreras; c) De Nivel de Control: la Comisión de Control de Gestión y la Auditoría Interna; y d) Los Cuerpos Auxiliares: los Claustros de Profesores, el Consejo General de Carrera Docente; el Instituto de Previsión Social de la UNAH, y la Dirección de Educación Superior. (Artículo 6)

El Consejo Universitario es el órgano máximo de dirección superior, que está integrado por: a) Las Autoridades Universitarias: el Rector, los Decanos de Facultades, los Directores de Centros Universitarios y Centros Regionales y el Director de Educación Superior; b) Los Docentes representantes de cada una de las Facultades, de los Centros Universitarios y de los Centros Regionales Universitarios; c) Los Estudiantes, representantes también de cada una de las Facultades, Centros Universitarios y Centros Regionales Universitarios; y d) la Representación de la Sociedad Civil por medio del Secretario Ejecutivo del Foro Nacional de Convergencia o institución equivalente. (Artículo 7). Es una de las atribuciones del Consejo Universitario: Aprobar, previo dictamen de la Junta de Dirección Universitaria, la apertura, funcionamiento, fusión o supresión, de sus Facultades, Carreras, Centros Universitarios, Centros Regionales Universitarios e Institutos de Investigación Científica. (Artículo 10, numeral 16).

La Junta de Dirección Universitaria, es el órgano administrativo principal de la UNAH responsable de la planificación, organización, control administrativo y seguimiento de los resultados operativos de la institución. (Artículo 11). Algunas de 
las atribuciones de la Junta de Dirección Universitaria son: previo a la verificación realizada por el Consejo General de la Carrera Docente en cuanto a los requisitos, nombrar a los Decanos de Facultades, Directores de Centros Universitarios y Regionales; aprobar la organización interna, los lineamientos y normas académicas de la UNAH y vigilar su aplicación y efectividad siguiendo las orientaciones del Consejo Universitario. (Artículo 15, numerales 1 y 8 ).

La Rectoría es la autoridad ejecutiva y ostenta la representación legal de la UNAH. Una de las atribuciones del Rector es nombrar, previo concurso público, al personal docente y administrativo en los términos que dispone la Ley Orgánica, los estatutos y reglamentos respectivos. (Artículos 17,19 numeral 9 literal a).

La UNAH para cumplir sus funciones, académicamente se encuentra estructurada en Facultades, Centros Universitarios y Centros Regionales Universitarios, Departamentos, Carreras e Institutos. (Artículo 28).

La estructura orgánica de las Facultades, Centros Universitarios y Centros Regionales Universitarios está integrada respectivamente por: 1) La Junta Directiva; 2) La Decanatura o la Dirección, en su caso; 3) La Secretaría; 4) El Claustro de Profesores; 5) Los Departamentos Académicos; 6) Los Coordinadores de Carrera; 7) El Comité Técnico de la Carrera; 8) El Consejo Local de Carrera Docente; y 9) Los Institutos. (Artículo 29).

Las Juntas Directivas están integradas por el Decano o Director en su caso, el Secretario, y por tres (3) representantes de los docentes y dos (2) representantes de los estudiantes. (Artículo 30). Los Decanos de las Facultades, los Directores de los Centros Universitarios y de los Centros Regionales, son nombrados por la Junta de Dirección Universitaria siguiendo los procedimientos legales establecidos. (Artículo 31). Las Secretarías son instancias dependientes de las Decanaturas o las Direcciones según el caso, que funcionan de conformidad con su reglamento respectivo. (Artículo 32). El Claustro de Profesores es el órgano académico que integra colegiadamente a todos los docentes de los Departamentos e Institutos de cada Facultad, Centro Universitario o Centro Regional Universitario, incorporados a la Carrera Docente. Se reúne para tratar asuntos académicos, elección de sus representantes ante los organismos de gobierno de la UNAH y para escoger los candidatos que serán propuestos para ocupar los cargos de gobierno de la UNAH, de conformidad con los reglamentos respectivos. (Artículo 33).

La Ley Orgánica explícitamente establece que la departamentalización es obligatoria en todas las unidades académicas de la Universidad. Que los 
Departamentos son las unidades académico administrativas encargadas del desarrollo de un campo específico del conocimiento, para lo cual desarrollarán carreras en los grados académicos establecidos por la Ley y sus Reglamentos. Las funciones, organización y atribuciones de los Departamentos se establecen en el reglamento respectivo. (Artículo 34).

La Coordinación de Carrera es la instancia encargada de la administración académica de un plan curricular. En cada Carrera debe funcionar un Comité Técnico, presidido por el Coordinador de Carrera e integrado por dos (2) representantes del Claustro de Profesores, dos (2) representantes de laAsociación de Estudiantes de la Carrera y dos representantes del colegio profesional universitario respectivo. El funcionamiento de las carreras es regulado por el reglamento respectivo. (Artículo 35).

Los Consejos Locales de la Carrera Docente se rigen por la reglamentación correspondiente. (Artículo 36).

Los Institutos son unidades académicas especializadas que se organizan en cada Facultad o Centro, y mediante las cuales cada disciplina académica focaliza temas y problemas de su propio campo, para dominar, conservar, incrementar, cuestionar y proyectar los saberes y las experiencias académicas superiores que por afinidad le corresponden. Un reglamento regulará la naturaleza, los contenidos, la estructura y las funciones de los institutos. (Artículo 37).

Reglamento de la Ley Orgánica.dèla UNAH (2007)

Al desarrollar los artículos de la Ley Orgánica, el Reglamento de la Ley Orgánica establece que:

Una de las funciones del Consejo Universitario es, aprobar los criterios para determinar la creación, funcionamiento, reestructuración o supresión de Facultades, Centros Universitarios, Centros Regionales Universitarios, Carreras, Departamentos, Observatorios e Institutos, considerando lo establecido en la Ley Orgánica, su Reglamento y el Plan General de Desarrollo de la UNAH. (Artículo 27, literal $k$ ).

Para la Junta de Dirección Universitaria establece, entre otras funciones, aprobar y proceder a la reestructuración interna de la UNAH, tanto administrativa como financiera y vigilar su aplicación y efectividad, siguiendo las orientaciones del Consejo Universitario. (Artículo 28, literal j). Y como funciones adicionales establece que la Junta de Dirección Universitaria, además de lo dispuesto en el 
artículo 15 de la Ley Orgánica y el Artículo 27 del Reglamento de la Ley, emitirá dictamen para que sea conocido por el Consejo Universitario, en aspectos que le competen, como órgano administrativo principal de la UNAH, cuando se trate de resolver sobre la apertura, funcionamiento, reestructuración, fusión o supresión de Facultades, Centros Universitarios, Centros Regionales Universitarios, Departamentos, Carreras, Observatorios o Institutos de la UNAH. (Artículo 29).

Aclara este Reglamento que no podrá recaer acuerdo o resolución de la Junta de Dirección Universitaria relativo a una Facultad, Centro, Departamento, Carrera, Observatorio o Instituto, sin haber oído previamente al respectivo Decano, Director, Jefe de Departamento, Coordinador de Carrera, Claustro de Profesores o Asamblea de Docentes. (Artículo 31).

Establece que la Secretaría General es el órgano de comunicación oficial, interna y externa de la UNAH, y para recibir las comunicaciones, demandas, reclamos o peticiones dirigidas al Consejo Universitario, al Rector, a la Secretaría General y a los Vicerrectores, a los Decanos o Directores de Centros Universitarios y Regionales que presenten autoridades nacionales o universitarias, estudiantes, docentes y los particulares, y darles el curso ordenado en los procedimientos administrativos, judiciales y financieros correspondientes. (Artículo 57, literal d). Es en este Reglamento (Artículo 78) adonde se define lo que es una Facultad, un Centro Universitario y un Centro Regional Universitario. Para los dos primeros la definición es la siguiente:

Facultad: es una unidad académica administrativa que desarrolla determinadas áreas afines del conocimiento que estructura y divide en uno o varios planes de estudio que conforman una o varias carreras para la formación profesional de los estudiantes. La Facultad se organiza en departamentos académicos e Institutos que realizan las funciones de docencia a las carreras, generan investigación, vinculan a las facultades con la sociedad y realizan gestión académica.

Centro Universitario: es la unidad académico administrativa que desarrolla a nivel superior campos del conocimiento de las ciencias básicas y las artes (naturales, matemáticas, sociales, humanísticas, artísticas y deportivas) dando servicio de ellas a las distintas carreras de las facultades y, además, crea en cada una de las ciencias básicas y las artes uno o varios planes de estudio que conforman una o varias carreras para la formación profesional de los estudiantes. El Centro Universitario se organiza en departamentos académicos e Institutos que realizan las funciones de docencia a las 
carreras de las Facultades y a las propias del Centro, generan investigación, vinculan a las facultades con la sociedad y realizan gestión académica.

Se aclara también que la Facultad, el Centro Universitario y el Centro Regional Universitario son las unidades de representación a través de las cuales se nombran los miembros de los órganos colegiados generales de la Universidad, salvo excepciones que el mismo Reglamento establece. (Artículo 78).

Como Reglas de organización y funcionamiento, se establece que es el Reglamento de Facultades, Centros Universitarios y Centros Regionales el que normará los distintos aspectos de organización, funcionamiento, régimen jurídico y administrativo, así como, en su caso, las Comisiones y competencias que se les atribuyan, siempre y cuando no contradigan disposiciones de la Ley Orgánica y el Reglamento de la Ley. (Artículo 79). La creación, orientación y reorientación del funcionamiento de Centros Universitarios, Centros Regionales Universitarios y las Facultades, se racionalizará considerando: los planes nacionales de desarrollo, la política de expansión de la UNAH dentro del marco de su Plan General de Desarrollo Integral, la adopción de nuevos modelos académicos y de universidad, la regionalización y orientación de sus proyectos teniendo en cuenta tanto las necesidades de la región y su recurso humano, como las condiciones de funcionamiento y la necesaria e igual calidad académica en los centros ya existentes. (Artículo 80).

Son competencias de las Facultades, Centro Universitario y Centros Regionales Universitarios (Artículo 81):

a) Proponer el desarrollo de nuevos campos del conocimiento, nuevas disciplinas, investigación y vinculación con la sociedad, en función de las necesidades de la región, el país y la Institución;

b) Proponer para su aprobación los planes de estudio de nuevas carreras y modificación de las existentes;

c) Promover y desarrollar procesos de calidad en la docencia y participar en la evaluación y acreditación de carreras y programas, de desarrollo curricular, actividades del personal docente y de administración y servicios adscritos a la Facultad o Centro;

d) Coordinar los servicios, mantener y mejorar las instalaciones necesarias para el desarrollo de la actividad académica de aprendizaje, investigación y vinculación;

e) Coordinar el proceso académico y administrativo de todas las unidades 
adscritas;

f) Promover y organizar actividades de investigación, vinculadas con la sociedad, formación permanente de docentes a través de los Departamentos, Observatorios e Institutos;

g) Participar en los procesos de matrícula, formación de expedientes de los estudiantes, traslados y certificaciones académicos de los estudiantes, así como las propuestas de equivalencias, convalidación y demás actuaciones similares de gestión académica;

h) Coordinar las actividades del sistema de ingreso, permanencia y egreso de los estudiantes conforme a la normativa vigente;

i) Organizar y proponer al Rector para su nombramiento o remoción, su plantilla de personal docente, de administración y de servicio, según los trámites establecidos en el Estatuto del Docente y el Contrato Colectivo;

j) Administrar con transparencia y eficacia sus presupuestos y gestionar los medios materiales de conformidad con la planificación económica y el SIAFI;

k) Proponer la creación, modificación, fusión o supresión de departamentos, observatorios, institutos y carreras, tomando en cuenta los criterios establecidos en el Reglamento de la Ley y en los atinentes;

I) Cooperación con los demás órganos de la Universidad en la realización de sus funciones;

m) Cumplir cualquier otro cometido asignado por las leyes, el Reglamento de la Ley y demás normas de aplicación.

Es en este Reglamento también donde se establece que los procedimientos para crear, modificar y suprimir las distintas unidades académicas y campos del conocimiento, quedan sometidos a las siguientes disposiciones (Artículo 82):

a) La creación, modificación y supresión de las Facultades, Centros Universitarios, Centros Regionales Universitarios, Carreras, Departamentos e Institutos, así como la implantación y supresión de campos del conocimiento, serán propuestas y aprobadas por el Consejo Universitario, previo dictamen de la Junta de Dirección Universitaria quien tomará en cuenta la Ley de Educación Superior y el dictamen de la Dirección de Docencia, el cual incluirá la opinión razonada de la Secretaría de Administración y Finanzas;

b) Además de lo establecido en el artículo 74 de la Racionalidad, se tomará en cuenta la existencia de otros centros, carreras, adscripción a departamentos, infraestructura y medios materiales existentes, acompañando el proyecto, si procede, de las dotaciones necesarias;

c) En estos procedimientos se abrirá un período de información pública y, en todo 
caso, las Facultades o Centros, Departamentos, Carreras e Institutos afectados en los procedimientos de elaboración de las correspondientes propuestas, deberán ser escuchados obligatoriamente.

En cuanto a la composición de una Facultad o Centro, se establece que está integrada por: el personal docente adscrito a sus departamentos académicos; el alumnado matriculado en las carreras adscritas a cada Facultad o Centro; y por el personal administrativo y de servicio adscrito a la Facultad o Centro. Se aclara que el personal docente y el personal administrativo y de servicio no podrán estar adscritos a más de una Facultad o Centro, excepto en el caso de aquel personal docente cuya movilidad sea exigida por su carga académica. (Artículo 83).

\section{Reglamento del Consejo Universitario (2005)}

En este Reglamento se establece que el Consejo Universitario aprobará, previo dictamen de la Junta de Dirección Universitaria y del Consejo de Educación Superior, la apertura, funcionamiento, fusión o supresión de Facultades, Carreras, Centros Universitarios, Centros Regionales Universitarios e Institutos de Investigación Científica. (Artículo 47). Reglamento de Juntas Directivas y de las Facultades, Centros Universitarios y Centros Regionales Universitarios (2007). En este Reglamento nuevamente se vuelve a definir (Artículo 1) lo que es una Facultad, Centro Universitario y Centro Regional Universitario. Para los dos primeros, las definiciones son aquí las siguientes:

Facultad: Unidad básica académico-administrativa que desarrolla determinadas áreas afines del conocimiento, que se estructura y divide en uno o varios planes de estudio que conforman una o varias carreras para la formación profesional de los estudiantes. La Facultad se organiza en Escuelas, Departamentos Académicos, Carreras de pre y post grado e Institutos que realizan las funciones de docencia, generan investigación, vinculan a las Facultades con la sociedad y realizan gestión académica.

Centro Universitario: Unidad académico-administrativa de la UNAH, que integra varios campos del conocimiento sobre un tema específico de la realidad, orientado a contribuir a la solución de problemas nacionales por medio de estudios inter, multi y transdisciplinarios.

Se define por primera vez lo que es una Escuela, la unidad técnico administrativo que integra varias áreas afines para promover el desarrollo de un campo específico del conocimiento. (Artículo 1). 
La racionalidad en la creación de unidades académicas, modificación y supresión de unidades universitarias y campos del conocimiento, se vuelve a reglamentar de la misma manera que se hizo en el Reglamento de la Ley Orgánica. (Artículo 5).

Acerca de los procedimientos para crear, modificar, y suprimir las distintas unidades académicas y campos del conocimiento, establece (Artículo 6) que deben estar sujetos al diagnóstico de las necesidades, potencialidades y los recursos del desarrollo nacional y regional sometido a las siguientes disposiciones:

a) La creación, modificación y supresión de Facultades, Centros Universitarios y Centros Regionales Universitarios, Escuelas, Carreras, Departamentos e Institutos, así como la implantación y supresión de campos del conocimiento, serán aprobados por el Consejo Universitarios, previo dictamen de la Junta de Dirección Universitaria, quien tomará en cuenta la Ley de Educación Superior y el dictamen de la Vice Rectoría Académica, el cual incluirá además la opinión razonada de la Secretaría de Administración y Finanzas;

b) En los procedimientos arriba descritos se abrirá un período de información pública y en todo caso, las Facultades, Centros, Escuelas, Departamentos, Carreras e Institutos relacionados en los trámites de elaboración de las correspondientes propuestas, deberán ser escuchados obligatoriamente.

\section{Ley de Educación Superior (1989)}

Esta Ley establece que el Consejo de Educación Superior, es el órgano de dirección y decisión del sistema. Está integrado por el Rector de la Universidad, seis miembros representantes de la Universidad Nacional Autónoma de Honduras, y seis Directores 0 autoridad jerárquica superior de los centros de educación superior, electos por el Consejo Técnico Consultivo de los cuales, por lo menos tres corresponderán a los centros privados de educación superior, y por el titular de la Dirección de Educación Superior. (Artículo 12).

Entre las atribuciones del Consejo de Educación Superior está el aprobar la apertura, funcionamiento, fusión o supresión de carreras, escuelas, facultades, institutos y centros de investigación científica, así como los pianes curriculares y los programas especiales de nivel superior de las universidades particulares o privadas y de los centros estatales de Educación Superior, regidos mediante esta Ley. Es entendido que la aprobación de carreras, escuelas, facultades, institutos y centros de investigación científica, así como los planes curriculares y programas especiales en los centros de Educación Superior, se hará a petición de éstos. (Artículo 17, literal ch). 
La Dirección de Educación Superior emitirá opinión razonada, previamente a la resolución del Consejo de Educación Superior, entre otras cosas sobre la creación o supresión de carreras y unidades académicas en las instituciones autorizadas. (Artículo 24, literal c).

\section{Reglamento General de la Ley de Educación Superior (1989)}

En este Reglamento se estable que la Dirección de Educación Superior emitirá opinión razonada, de acuerdo a los requisitos y procedimientos reglamentarios, previamente a la resolución que deba emitir el Consejo de Educación Superior, entre otros asuntos, para la creación o supresión de carreras y unidades académicas en las instituciones autorizadas. (Artículo 43, literal c).

\section{PROCEDIMIENTO PARA CREACIÓN DE UNA FACULTAD O UN CENTRO EN LAUNAH}

El análisis de las diferentes leyes y reglamentos que regulan el funcionamiento de la Universidad Nacional Autónoma de Honduras revela que, el procedimiento para la creación de una Facultad o un Centro Universitario contempla los siguientes pasos:

1) El Decano, Director, Jefe de Departamento, Coordinador de Carrera, Claustro de Profesores o Asamblea de Docentes interesados, preparan un documento de Solicitud justificativo de la creación de una Facultad o un Centro.

2) Esta Solicitud se presenta a la Rectoria de la Universidad; y es por medio de la Secretaria General de la Universidad que se solicita que este asunto sea incluido como un punto de agenda en la próxima Sesión del Consejo Universitario.

3) Al ser incluido el punto en la agenda del Consejo Universitario, durante el desarrollo de la sesión este máximo Organismo de Gobierno Universitario da por recibida la Solicitud, y de inmediato pide la elaboración del correspondiente dictamen a la Junta de Dirección Universitaria. También solicita Dictamen a la Vicerrectoría Académica y a la Secretaría Ejecutiva de Administración y Finanzas. Adicionalmente puede pedirle dictamen a la Dirección de Docencia, al Abogado General de la Universidad, o a cualquier otra instancia o autoridad universitaria que considere pertinente.

4) Ante el pedido del Consejo Universitario, la Junta de Dirección Universitaria prepara su dictamen escuchando previamente al respectivo Decano, Director, Jefe de Departamento, Coordinador de Carrera, Claustro de Profesores o Asamblea de Docentes proponente. De igual manera procede la Vicerrectoría Académica, la Dirección de Docencia, la Secretaría Ejecutiva de Administración y Finanzas, el Abogado General de la Universidad, y cualquier otra instancia o 
autoridad universitaria a la que se le haya pedido elaborar un dictamen. Una vez elaborados los dictámenes, todos deben ser enviados a la Secretaría del Consejo Universitario.

5) Cuando todos los dictámenes solicitados han sido recibidos en la Secretaría del Consejo Universitario, el punto de la Solicitud de creación de la Facultad o Centro nuevamente es agendado, esta vez para su discusión y resolución.

6) En la sesión correspondiente, el Consejo Universitario conoce la solicitud de creación de la facultad o centro. Conoce todos los dictámenes elaborados al efecto. El Consejo Universitario, como máxima autoridad universitaria, resuelve lo que considera pertinente. En el caso de que la resolución sea favorable, comunica su acuerdo a la Junta de Dirección Universitaria para que proceda de conformidad.

\section{LA CREACIÓN DE LAFACULTAD DE CIENCIAS ESPACIALES DE LAUNAH}

El proceso formal de creación de la Facultad de Ciencias Espaciales de la Universidad Nacional Autónoma de Honduras (FACES/UNAH) fue marcado por cuatro hechos importantes:

1) Cuando la Directora del OACS/UNAH presentó la Solicitud para que el Honorable Consejo Universitario conociera la problemática del Observatorio Astronómico Centroamericano de Suyapa por no haber sido incluido en la nueva estructura universitaria.

Esta Solicitud se presentó a la Secretaría General de la UNAH mediante Oficio OACS-096/2008 de fecha 26 de Junio de 2008. Contenía varios documentos dirigidos al Rector de la UNAH, con la petición para que el Consejo Universitario conociera la problemática derivada de la aplicación del Acuerdo No. 368-2008 que con fecha 15 de mayo aprobó la Comisión de Transición. Los documentos incluidos eran: a) ¿Qué es el Observatorio Astronómico Centroamericano de Suyapa de la Universidad Nacional Autónoma de Honduras?, presentado a la Comisión de Transición en sesión del 26 de Febrero de 2008; b) Borrador del Acuerdo de Reconocimiento del Observatorio Astronómico de la UNAH como Observatorio Astronómico Centroamericano de Suyapa, Centro Universitario de Ciencias Espaciales de la Universidad Nacional Autónoma de Honduras, preparado el 10 de marzo de 2008 a petición de la Secretaría de la Junta de Transición; c) Oficio OACS-076/2008 de fecha 22 de mayo de 2008, con Carta Púbica dirigida al Rector de la UNAH en relación con los problemas derivados de la aplicación del Acuerdo No. 368-2008 de la Comisión de Transición. 
2) Cuando la Solicitud del Observatorio Astronómico Centroamericano de Suyapa fue admitida por parte del Consejo Universitario, máximo organismo de gobierno universitario que previo a tomar cualquier decisión la remitió a la Junta de Dirección Universitaria, al Consejo de Educación Superior y a la VicerrectoríaAcadémica para solicitarles dictámenes.

En la Sesión Extraordinaria del Honorable Consejo Universitario celebrada el jueves 31 de julio del año dos mil ocho, en Acta Número 001-07-2008, levantada al efecto, obra elAcuerdo que en su parte resolutiva dice:

\section{ACUERDO NÚMERO CU-E-009-07-2008}

CONSIDERANDO: Que la honorable Comisión de Transición emitió el Acuerdo número trescientos sesenta y ocho (No.368-2008), relativo a la organización de una nueva estructura académica de la Universidad Nacional Autónoma de Honduras, en el que no se señala de manera expresa la ubicación del Observatorio Astronómico Centroamericano de Suyapa.

CONSIDERANDO: Que la Señora Directora del Observatorio Astronómico Centroamericano de Suyapa, Dra. MARIA CRISTINA PINEDA DE CARIAS, ha presentado formal propuesta ante la Rectoría de la Universidad Nacional Autónoma de Honduras (UNAH), a fin que el Consejo Universitario adopte un Acuerdo orientado a reconocer al Observatorio Astronómico Centroamericano de Suyapa, como parte de la nueva estructura Universitaria, haciendo público en este acto el borrador de Acuerdo, que en su oportunidad conoció la Honorable Comisión de Transición sin emitir ni aprobar el reconocimiento correspondiente del Observatorio Astronómico Centroamericano de Suyapa, como un Centro Universitario de Ciencias Espaciales.

CONSIDERANDO: Que el Consejo Universitario debe generar amplias discusiones en relación a asuntos de orden académico que permitan adoptar decisiones que fortalezcan el quehacer de nuestra Alma Máter.

POR TANTO: El Consejo Universitario, en uso de sus facultades establecidas en el Artículo No.10, numeral 5 y el artículo 47 de su Reglamento Interno, ACUERDA:

PRIMERO: Remitir a la Honorable Junta de Dirección Universitaria para que brinde Dictamen sobre la creación del Centro Universitario o Facultad de Ciencias Espaciales, en reconocimiento al funcionamiento del Observatorio Astronómico Centroamericano de Suyapa. 
SEGUNDO: Solicitar a la Dirección de Educación Superior, para que turne al pleno del Consejo de Educación Superior con el propósito que dictamine sobre esta iniciativa.

TERCERO: En los mismos términos solicitar a la Vice Rectoría Académica de la Institución a efecto que rinda dictamen al respecto. COMUNIQUESE.

3) Cuando a petición de la Directora del Observatorio Astronómico el Honorable Consejo Universitario nuevamente conoce la solicitud, pero que para tener mejores criterios resolvió pedir a la Vicerrectoría Académica que conjuntamente con la Dirección del Observatorio Astronómico Centroamericano de Suyapa elaboraran criterios que posibilitaran la creación de la Facultad de Ciencias Espaciales; pidiendo además los dictámenes del Abogado General de la Universidad y de la Secretaria de Administración y Finanzas.

En la Sesión Ordinaria Consejo Universitario celebrado el 18 de Diciembre de 2008, en el Acta Número 005-012-2008 levantada al efecto, aparece el Acuerdo que en su parte resolutiva dice:

\section{ACUERDO NÚMERO CU-0-069-012-2008}

CONSIDERANDO: Que el Consejo Universitario conoció en su Sesión extraordinaria celebrada el jueves treinta y uno de julio de dos mil ocho, según consta en el Acuerdo Número CU-E-009-07-2008, la propuesta presentada por la Directora del Observatorio Astronómico Centroamericano de Suyapa, en el sentido que se reconozca esta dependencia como Centro Universitario o Facultad de Ciencias Espaciales, solicitando para ello los dictámenes de la Junta de Dirección Universitaria, Consejo de Educación Superior y la VicerrectoraAcadémica.

CONSIDERANDO: Que los dictámenes conocidos por diferentes razones, no favorecen a que se cree en este momento esa Unidad académica, razón por lo que este Organismo de Gobierno, en reconocimiento a los importantes aportes científicos, académicos y técnicos del OACS/UNAH, ve como pertinente la necesidad de profundizar sobre esta petición a efecto de adoptar una decisión que sea coherente con el proceso de reforma a la que la Institución se encuentra avocada.

POR TANTO: El Consejo Universitario en 9aplicación a los artículos 10) literal 16, yArtículo 27 literal k) del Reglamento General de la Ley, ACUERDA:

PRIMERO: Abstenerse de pronunciarse en la presente sesión sobre la petición 
de creación del Centro Universitario o Facultad de Ciencias Espaciales, presentada por la Directora del Observatorio Astronómico Centroamericano de Suyapa (OACS/UNAH); con la finalidad de que la Vicerrectora Académica y la Dirección del OACS/UNAH trabajen conjuntamente en la elaboración de criterios que posibiliten la creación de dicha unidad académica.

SEGUNDO: Solicitar a la Oficina del Abogado General y a la Secretaría Ejecutiva de Administración y Finanzas el dictamen correspondiente al respecto.

TERCERO: Conocer y resolver lo procedente sobre este particular en la segunda sesión ordinaria establecida en el Calendario de Sesiones Ordinarias del Consejo Universitario, para el año dos mil nueve.

CUARTO: El presente Acuerdo es de ejecución inmediata. COMUNIQUESE.

4) Finalmente el Honorable Consejo Universitario, después de haber escuchado todos los dictámenes y criterios que consideró conveniente, resolvió la creación de la Facultad de Ciencias Espaciales en reconocimiento al funcionamiento del Observatorio Astronómico Centroamericano de Suyapa.

En la Sesión Ordinaria celebrada los días viernes 27 de marzo y viernes 17 de abril del año dos mil nueve, en el Acta Número 003-03-2009, levantada al efecto, obra el Acuerdo que en su parte resolutiva dice:

\section{ACUERDO NÚMERO CU-0-043-03-2009}

CONSIDERANDO: Que el Consejo Universitario Máximo Órgano de Dirección Superior responsable de concertar y generar las políticas y estrategias de la gestión universitaria.

CONSIDERANDO: Que el Consejo Universitario en Sesión Ordinaria del 18 de diciembre de 2008 , se abstuvo de pronunciarse sobre la petición de Creación del Centro Universitario o Facultad de Ciencias Espaciales presentada por la Dra. María Cristina Pineda de Carías, Directora del Observatorio Astronómico Centroamericano de Suyapa, con el propósito de que la Vicerrectoría Académica y la Dirección del OACS/UNAH, trabajaran conjuntamente en la elaboración de criterios para posibilitar la creación de dicha unidad; asimismo se solicitó dictamen sobre este asunto a la Oficina del Abogado General y a la Secretaría Ejecutiva de Administración y Finanzas.

CONSIDERANDO: Que las Unidades mencionadas emitieron los criterios y dictámenes correspondientes. 
POR TANTO: El Consejo Universitario en aplicación del Artículo 10, numeral 16), de la Ley Orgánica de la Universidad Nacional Autónoma de Honduras, Artículo 47 de su Reglamento Interno y Artículo 27, literal k) del Reglamento General de la Ley,ACUERDA:

PRIMERO: Aprobar la Creación de la Facultad de Ciencias Espaciales en reconocimiento al funcionamiento del Observatorio Astronómico Centroamericano de Suyapa (OACS/UNAH).

SEGUNDO: El presente acuerdo es de ejecución inmediata. COMUNIQUESE.

\section{DISCUSIÓNYCONCLUSIONES}

La creación de la Facultad de Ciencias Espaciales por parte del Honorable Consejo Universitario ha venido a poner de manifiesto que en la UNAH la estructura organizativa no es rígida, antes bien, que la nueva reglamentación existente y los procesos de reforma universitaria ya iniciados son lo suficientemente flexibles como para poder dar espacio a la creación de nuevas unidades académicas cuyo funcionamiento se considere pertinente y de beneficio, tanto para los actuales como para las futuras generaciones de profesionales universitarios, capaces de participar en la transformación de la sociedad hondureña para impulsar el desarrollo económico, político, social, humano y sostenible de Honduras.

La creación de la Facultad de Ciencias Espaciales en la Universidad Nacional Autónoma de Honduras ha sido un logro muy importante que ha colocado a la Institución en una posición de liderazgo en la región centroamericana. Desde finales de los años ochenta, el Programa de Aplicaciones Espaciales de las Naciones Unidas había venido apoyando el establecimiento y operación de centros para la educación en la Ciencia y la Tecnología Espaciales en África, Asia y el Pacífico, América Latina y el Caribe, y en el Oeste de Asia. En Honduras, la creación de la Facultad de Ciencias Espaciales teniendo como base el Observatorio Astronómico Centroamericano de Suyapa, abre el espacio y estimula el desarrollo simultaneo de la Astronomía y la Astrofísica, de la Ciencia y las Tecnologías de la Información Geográfica, de la Arqueoastronomía, y de otros campos afines, con renovados enfoques.

Con el caso de la creación de la Facultad de Ciencias Espaciales de la UNAH en Honduras, de nuevo se comprueba, como decía Haubold (2003), que la incorporación de elementos de ciencia y tecnologías espaciales en los planes de estudios universitarios, puede servir un doble propósito tanto para los países 
desarrollados como en desarrollo. Permite que las naciones tomemos ventaja de los beneficios inherentes a las nuevas tecnologías, las cuales en muchos casos, tienen como plataforma de lanzamiento la ciencia y las tecnologías espaciales. Pueden también revitalizar los sistemas educativos, al introducir los conceptos de las altas tecnologías de una manera no esotérica y pueden ayudar a crear capacidades nacionales en ciencia y tecnología en general. Y adicionalmente, citando a Pyenson y Sheets-Pyenson: "Los campos emergentes del conocimiento llegan a ser nuevas disciplinas cientificas solamente después que ellas han encontrado un lugar seguro en las universidades. Uno mira a las universidades como la palabra autorizada acerca de las últimas innovaciones. Las nuevas ideas científicas emergen en una gran variedad de maneras, pero ellas sólo llegan a ser patrimonio común de la Humanidad cuando han sido procesadas por una institución para la formación avanzada como la universidad moderna."

La creación de la Facultad de Ciencias Espaciales ha hecho posible llevar la reforma universitaria al Observatorio Astronómico Centroamericano de Suyapa, de variadas maneras. Ha permitido la organización de los departamentos académicos por el agrupamiento de los profesores que trabajan en diferentes campos y disciplinas del conocimiento (Clasificación UNESCO): Astronomía y Astrofísica (21), Ciencia y Tecnologías de la Información Geográfica (2504, 2505, 3324, 3329), Arqueoastronomía (campo emergente) y otros afines. Ha permitido intensificar y profundizar las dimensiones del trabajo académico que los profesores e instructores realizan de manera integral como actividades de docencia, investigación científica, vinculación con la sociedad, administración y gestión, orientación, capacitación y producción. Demanda ahora de manera clara cuáles son los programas de formación de los profesionales universitarios de pregrado y de postgrado que debemos desarrollar. Por los servicios docentes y los planes de estudios de las propias carreras, identifica meridianamente quienes son los estudiantes de la Facultad de Ciencias Espaciales y cuáles los procesos académicos que hay que fortalecer en beneficio de su formación. A nivel institucional deja claro cómo es que los profesores y estudiantes de la nueva unidad académica, participarán en los organismos de gobierno universitario.

El reto para promover el propio desarrollo del campo de las Ciencias Espaciales, a nivel institucional, nacional e internacional está planteado. Toca ahora que las autoridades universitarias aprueben la estructura de los puestos de gobierno de la nueva Facultad tales como, el puesto de Decano(a), Secretario(a), los puestos de Jefes de Departamento y Coordinadores de Carrera, así como las nuevas plazas permanentes del personal docente y administrativo que permita cumplir con los estándares mínimos fijados por la Ley para el cumplimiento de las obligaciones y 
responsabilidades asignadas. En lo que a los profesores, instructores, estudiantes y personal administrativo respecta, se tiene la confianza que al igual que se hizo en los últimos quince años para llevar el nombre del Observatorio Astronómico Centroamericano de Suyapa de la Universidad Nacional Autónoma de Honduras, bastante más allá de las fronteras centroamericanas, el nombre de la recién creada Facultad de Ciencias Espaciales resonará en diferentes lugares del Planeta.

\section{BIBLIOGRAFÍA}

Consejo Superior Universitario Centroamericano. Acta LXXX Sesión Ordinaria. Punto Séptimo: Reconocimiento de la Categoría Regional Centroamericana de Programas de Postgrado evaluados en el marco del SICAR. Tegucigalpa: Noviembre 2006.

Consejo Universitario UNAH. Acuerdo Número CU-0-043-03-2009. Sesión Ordinaria. Acta Número 003-03-2009. Ciudad Universitaria, Tegucigalpa. 27 de marzo y 17 de abril de 2009.

Consejo Universitario UNAH. Acuerdo Número CU-0-069-012-2008. Sesión Ordinaria. Acta Número 005-012-2008. Ciudad Universitaria, Tegucigalpa. 18 de Diciembre de 2008.

Convenio Específico entre el Observatorio Astronómico Centroamericano de Suyapa de la Universidad Nacional Autónoma de Honduras y el Departamento de Geografía de la Universidad de Alcalá para el desarrollo de la Maestría en Ordenamiento y Gestión del Territorio. 2007.

Convenio Marco de Cooperación Internacional entre la Universidad Nacional Autónoma de Honduras y la Universidad de Alcalá de España. Alcalá de Henares, España. Tegucigalpa, Honduras. 2007.

Haubold, Hans J. Education curricula of the UN-affiliated regional Centres for Space Science and Technology Education. Space Policy. 19: 67-69. Elsevier Science Ltd. 2003.

Haubold, H. J. y W. Wamstaker. The UN/ESAWorkshops on Basic Space Science in Developing Countries. En: Developing Basic Space Science Worldwide, a decade of UN/ESA Workshops. Netherlands: Kluwer Academic Publishers; 2004.

Ley de Educación Superior. Decreto Legislativo Número 142-89. La Gaceta; Diario Oficial de la República de Honduras. Número 25,961. Tegucigalpa M. D. C., Honduras. 17 de Octubre de 1989.

Maestría en Ordenamiento y Gestión del Territorio, $2^{a}$ ed. Proyectos Conjuntos de Docencia. Programa de Cooperación Interuniversitaria e Investigación Científica. Agencia Española de Cooperación Internacional para el Desarrollo (AECID). Diciembre, 2007. 
Maestría en Ordenamiento y Gestión del Territorio. $2^{\mathrm{a}}$ ed. Proyectos Conjuntos de Docencia. Programa de Cooperación Interuniversitaria e Investigación Científica. Agencia Española de Cooperación Internacional para el Desarrollo (AECID). Diciembre, 2008.

ONU. Asamblea General. VII Taller Naciones Unidas/Agencia Espacial Europea sobre Ciencia Espacial Básica. Informe. Comisión sobre utilización del espacio ultraterrestre con fines pacíficos. A/AC.105/682. Enero, 1998.

Pineda de Carías, María Cristina. Science and Spatial Technology for Honduras' benefit. HONDURAS, Proyecto Reconstrucción Post Mitch. USAID - USGS, CIGEO-UNITEC. Tegucigalpa: 2001.

Pineda de Carías, María Cristina. ¿Qué es el Observatorio Astronómico Centroamericano de Suyapa de la Universidad Nacional Autónoma de Honduras? Tegucigalpa: 2008.

Pineda de Carías, María Cristina. The Central American Master's Program in

Astronomy and Astrophysics. En: Astronomy for Developing Countries. International Astronomical Union. United States of America: The Astronomical Society of the Pacific; 2001.

Plan de Estudios de la Carrera de Ordenamiento y Gestión del Territorio en el grado de Maestría. Universidad Nacional Autónoma de Honduras, Observatorio Astronómico Centroamericano de Suyapa; Universidad de Alcalá, España, Departamento de Geografía; Secretaría de Estado en los Despachos de Gobernación y Justicia, Unidad Coordinadora de Proyectos. Tegucigalpa: 2005. Programa de Postgrado en Cartografía, SIG y Teledetección. Máster Universitario, Departamento de Geografía, Universidad de Alcalá. Alcalá de Henares, España. 2004.

UNESCO. Nomenclatura Internacional Normalizada para los Campos de la Ciencia

y la Tecnología. Clasificación UNESCO. Disponible en: http://www.et.bs.ehu.es/varios/unesco2.php. Agosto, 2008.

United Nations. Remote Sensing and the Geographic Information System (GIS) Education Curriculum. Office for Outer Space, ST/SPACE/18. New York: United Nations; 2003.

Universidad Nacional Autónoma de Honduras. Comisión de Transición. Acuerdo Número Trescientos Sesenta y Ocho (No. 368-2008). Oficio No. CT-UNAH-4922008. Tegucigalpa: 15 de mayo de 2008.

Universidad Nacional Autónoma de Honduras. Comisión de Transición. Reglamento de Juntas Directivas y de las Facultades, Centros Universitarios y Centros Regionales Universitarios. Acuerdo No. 299-2007. La Gaceta; Diario Oficial de la República de Honduras. Número 31,450. Tegucigalpa: 6 de Noviembre de 2007. 
Universidad Nacional Autónoma de Honduras. Comisión de Transición. Reglamento de la Ley Orgánica de la UNAH. Acuerdo No. 206-07. La Gaceta; Diario Oficial de la República de Honduras. Año CXXX, Número 31,379. Tegucigalpa: 11 de Agosto de 2007.

Universidad Nacional Autónoma de Honduras. Comisión de Transición. Reglamento del Consejo Universitario. Acuerdo No. 09-CTUNAH-2005. La Gaceta; Diario Oficial de la República de Honduras. Número 30,768. Tegucigalpa: 6 de Agosto de 2005.

Universidad Nacional Autónoma de Honduras. Consejo de Educación Superior. Acuerdo de Aprobación de la Carrera y Plan de Estudios Programa de Postgrado de Astronomía y Astrofísica de la UNAH 1974-215-08. Libro de Registro de Aprobación de Carreras y Planes de Estudio de la Dirección de Educación Superior Tomo IV-08, Folio 316, Registro RP®-132-05-08. Tegucigalpa: Marzo, 2008.

Universidad Nacional Autónoma de Honduras. Consejo de Educación Superior. Acuerdo de Aprobación de la Carrera y el Plan de Estudios de Ordenamiento y Gestión del Territorio de la UNAH No. 1447-185-05. Libro de Registro de Aprobación de Carreras y Planes de Estudios de la Dirección de Educación Superior Tomo IV-05, Folio No. 149, Registro RP-239-10-05. Septiembre, 2005. Universidad Nacional Autónoma de Honduras. Consejo de Educación Superior. Reglamento de la Ley de Educación Superior. La Gaceta; Diario Oficial de la República de Honduras. Tegucigalpa: Diciembre, 1989.

Universidad Nacional Autónoma de Honduras. Consejo Universitario. Acuerdo

Número CU-E-009-07-2008. Sesión Extraordinaria, Acta Número 001-07-2008.

Ciudad Universitaria, Tegucigalpa. 31 de julio de 2008.

Universidad Nacional Autónoma de Honduras. Ley Orgánica de la Universidad Nacional Autónoma de Honduras (UNAH). Decreto Legislativo No. 209-2004. La Gaceta; Diario Oficial de la República de Honduras. No. 30,621. Año CXXVIII, Tegucigalpa: 12 de Febrero de 2005.

Universidad Nacional Autónoma de Honduras. Observatorio Astronómico Centroamericano de Suyapa. Plan de Estudios del Programa de postgrado Regional Centroamericano de Astronomía y Astrofísica en el grado de Maestría. Tegucigalpa: febrero, 2008.

Universidad Nacional Autónoma de Honduras. Reformas a la Ley Orgánica de la Decreto Legislativo No. 13-2006. Tegucigalpa: 9 de marzo de 2006. 